\title{
Multi-glioblastoma-peptide-targeting Autologous Dendritic Cell Vaccine ICT-107
}

\author{
National Cancer Institute
}

\section{Source}

National Cancer Institute. Multi-glioblastoma-peptide-targeting Autologous Dendritic Cell

Vaccine ICT-107. NCI Thesaurus. Code C124054.

A cell-based cancer vaccine composed of autologous dendritic cells (DCs) pulsed with six synthetic glioblastoma (GBM) peptides: absent in melanoma 2 (AIM-2), melanomaassociated antigen 1 (MAGE-1), tyrosinase-related protein 2 (TRP-2), glycoprotein 100 (gp100), epidermal growth factor receptor 2 (HER-2), interleukin-13 receptor subunit alpha-2 (IL-13Ra2), with potential immunostimulatory and antineoplastic activities. Mononuclear cells obtained via leukapheresis are differentiated into DCs, and pulsed with the GBM-associated peptides. Upon administration, multi-glioblastoma-peptidetargeting autologous DC vaccine ICT-107 exposes the immune system to GBMassociated antigens, which activates a specific cytotoxic T-lymphocyte (CTL) response against GBM cells. This leads to GBM cell lysis. The six peptides are derived from tumor associated antigens (TAA) expressed on GBM cells and cancer stem cells (CSCs). GBM stem-like cells contain a specific range of antigens that are essential for the neoplastic growth and survival of GBM cells. 